\title{
Role of NBI and WLE in Diagnosis of Barrett's Esophagus in Patients with Chronic Gastroesophageal Reflux Disease
}

\author{
Enaase Barakat, Maha Ragab Habeeb, Neven Farouk Abass
}

\begin{abstract}
Department of Internal Medicine, Gastroenterology and Hepatology Unit, Faculty of Medicine, Mansoura University, Egypt

Correspondence to: Maha Ragab Habeeb, Department of Internal Medicine, Gastroenterology and Hepatology Unit, Faculty of Medicine, Mansoura University, Egypt
\end{abstract}

Email:

maha_ragab68@yahoo.com

Received: 25 November 2020

Accepted: 4 April 2021

\begin{abstract}
Background: Recent data have emerged that a targeted biopsy technique using Narrow-Band Imaging (NBI) could be considered in patients undergoing surveillance for Barrett's esophagus (BE). Aim of the study: to determine the role of NBI compared to conventional- white light endoscopy (WLE) in diagnosis of Barrett's esophagus in patients with chronic gastroesophageal reflux disease. Patients and methods: the study included 274 patients with chronic reflux symptoms, conventionalwhite light endoscopy (WLE) was done in all cases for diagnosis of BE. Ninety patients showed Barrett's mucosa pattern by white-light endoscopy so 4-random biopsies were taken and examined by histopathology for detection of columnar-lined intestinal metaplasia, then patients who showed negative histopathology for intestinal metaplasia were re-endoscopied and NBI targeted biopsies were taken for histopathological confirmation of presence of intestinal metaplasia. Based on histopathology results, patients were divided into 2 groups,
\end{abstract} group 1 (B E positive, 80 patients) and group 2 (BE negative, 10 patients). Group showed increased detection rates in age > 30 years. Results: 90 patients had columnar-lined epithelium (CLE) by WLE (32.8\%); Seventy- three patients with 4 quadrant biopsy technique confirmed to have intestinal metaplasia $(81.1 \%$ of cases with endoscopic BE, and $26.6 \%$ of all screened patients), 17 patients with negative histopathology for BE were re-examined endoscopically and NBI - targeted biopsies were taken, 7 patients of them showed intestinal metaplasia, so total patients confirmed to have BE has risen to 80 patients (88.9\%). Conclusion: NBI- targeted biopsies could diagnose BE in patients tested negative by WLE taken biopsies

Key words: Barrett's, reflux, narrow band imaging, white light endoscopy. 



\section{Introduction:}

Barrett's esophagus (BE) is the only known precursor lesion to esophageal adenocarcinoma (1) which has now become the fifth leading cause of cancer-related death in men worldwide (2)

The prevalence of BE has increased in recent years, it has been detected in about $15 \%$ of patients with chronic GERD and in approximately1-2\% of population subjects $(3,4)$ Increasing age, male gender, tobacco smoking have been proved to be risk factors for $\mathrm{BE}$, moreover, obesity, positive family history, metabolic syndrome, type 2 diabetes mellitus, and sleep apnea have been identified as potential BE risk factors (5).

Endoscopic surveillances of $\mathrm{BE}$ has been recommended in various guidelines by different gastroenterological societies, and so, has been widely implemented. (6-11)

The gold standard diagnosis of BE is white light endoscopy (WLE) with multiple biopsies according to the Seattle protocol. This involves biopsies at $1-2 \mathrm{~cm}$ in a quadrantic approach. However, WLE is associated with limited sensitivities, biopsy sampling errors, significant cost, and poor adherence to the Seattle protocol, so ,there has been a tendency to use enhanced imaging to eliminate the need for excessive biopsies as per the Preservation and Incorporation of Valuable Endoscopic Innovations (PIVI) initiative (12).

Recent data have emerged that a targeted biopsy approach using Narrow-Band Imaging (NBI) could be considered in patients undergoing surveillance for BE (13).

Narrow band imaging (NBI) is an advanced endoscopic technique concerned in the assessment of surface patterns and microvascular architecture by utilization of a narrowed spectrum light. Blue and green wavelengths are selected by optical filters, with the elimination of red light (14). These lights with narrowed bandwidths penetrate the superficial mucosal structures and are better absorbed by hemoglobin, yielding an enhancement of mucosal features and blood vessels (capillaries from superficial mucosal layer, deeper mucosal and submucosal vessels) $(15,16)$.

The aim of this study is to determine the role of NBI compared to conventional- white light endoscopy (WLE) in diagnosis of Barrett's esophagus in patients with chronic gastroesophageal reflux disease.

\section{Patients and methods:}

This was a prospective study including 274 patients with chronic reflux symptoms, selected from patients attending the inpatient 
and outpatient clinics of the gastroenterology and Hepatology unit at the Internal Medicine Department, Riyadh National Hospital, Saudi Arabia, between July 2012 and June 2015. All of the patients provided written informed consent. The Institutional Review Board (IRB) of Riyadh National Hospital approved the study.

Patients were included if they were adults (more than 18 years of age), of any gender, with chronic reflux symptoms and endoscopically-diagnosed BE. Patients were excluded if they have dysphagia, (barium study was done $1^{\text {st }}$ to exclude stricture) or if were unfit, or non- willing to do gastrointestinal endoscopy.

Patients' demographic data, history and examination findings including endoscopic findings were recorded.

Helicobacter pylori (H. pylori) was diagnosed by histopathological examination of gastric biopsy which is the gold slandered for diagnosis, 2 antral biopsies were taken (17), the presence of BE was diagnosed by WLE was reported as extension of salmon colored mucosa into esophagus $>1 \mathrm{~cm}$ proximal to the gastroesophageal junction (18). Multiple biopsies (four quadrant biopsies every $2 \mathrm{~cm}$, together with targeted biopsies of visible lesions -Seattle protocol) were taken for histopathological confirmation, Positive BE was determined by presence of columnar- lined intestinal metaplasia in esophageal biopsies (19)

Patients whose histopathological examination revealed no $\mathrm{BE}[\mathrm{no}=17]$, were reexamined and biopsied by NBI-targeted biopsy for detection of Barrett's mucosa by histopathology, based on histopathology results, patients were divided into 2 groups, group 1 (BE positive, 80 patients) and group 2 (BE negative, 10 patients)

\section{Statistical analysis:}

SPSS, version 18 (SPSS Inc. Chicago, IL), was used, independent $\mathrm{T}$ test, Chi- square test were used for analysis

\section{Results:}

The study included 274 patients with chronic reflux symptoms, 90 patients had columnarlined epithelium (CLE) (endoscopic BE) by WLE $(32.8 \%)$, they were 67 males and 23 females with mean age 54.63 years.

Columnar-lined intestinal metaplasia was used to diagnose $\mathrm{BE}$ by histopathological examination, it was detected in 80 patients of those with endoscopic BE (group 1), mean age for patients with $\mathrm{BE}$ was $43.3 \pm 11.07$, which was higher than patients with negative BE (30.3 \pm 10.8$)$, however, the difference was statistically insignificant (P: 0.56)

Age distribution of group 1 patients (positive $\mathrm{BE})$ showed increased detection rates in age 
$>30$ years, most of cases tested negative for $\mathrm{BE}$ (group 2) were in younger age group (below 30) (figure 1)

Sex distribution showed predominance of male patients in group 1 patients (62 males versus 18 females), while in group 2, male to female ratio was 1:1 (table 1)

Body Mass Index (BMI) was higher in group 1 patients $(29.2 \pm 6.8)$ than group 2 patients (27.3 \pm 7$)$, but the difference was statistically insignificant ( $\mathrm{P}:$ 0.7) (table 1). Whereas obesity was more frequent in group 1 patients (75\%), while $25 \%$ of them were either normal or underweight (table 2).

$\mathrm{H}$ pylori test was positive in 19 of group 1 patients, and 3 of group 2 patients, while most of patients with endoscopic BE tested negative for $\mathrm{H}$ pylori (68 patients out of 90 patients) (table 2)

Seventy-three patients- out of the ninety patients showed endoscopic BE, confirmed to have intestinal metaplasia by histopathology, biopsies were taken as 4 quadrant biopsies every $2 \mathrm{~cm}$, together with targeted biopsies of visible lesions (Seattle protocol) $(81.1 \%$ of cases with endoscopic BE, and $26.6 \%$ of all screened patients), 17 patients with negative histopathology for $\mathrm{BE}$ were re-examined endoscopically and NBI - targeted biopsies were taken for detection of BE, 7 patients of them proved to have columnar- lined intestinal metaplasia, so total patients confirmed to have $\mathrm{BE}$ has risen to 80 patients, out of 90 patients with endoscopic BE (88.9\%). (figure 2).

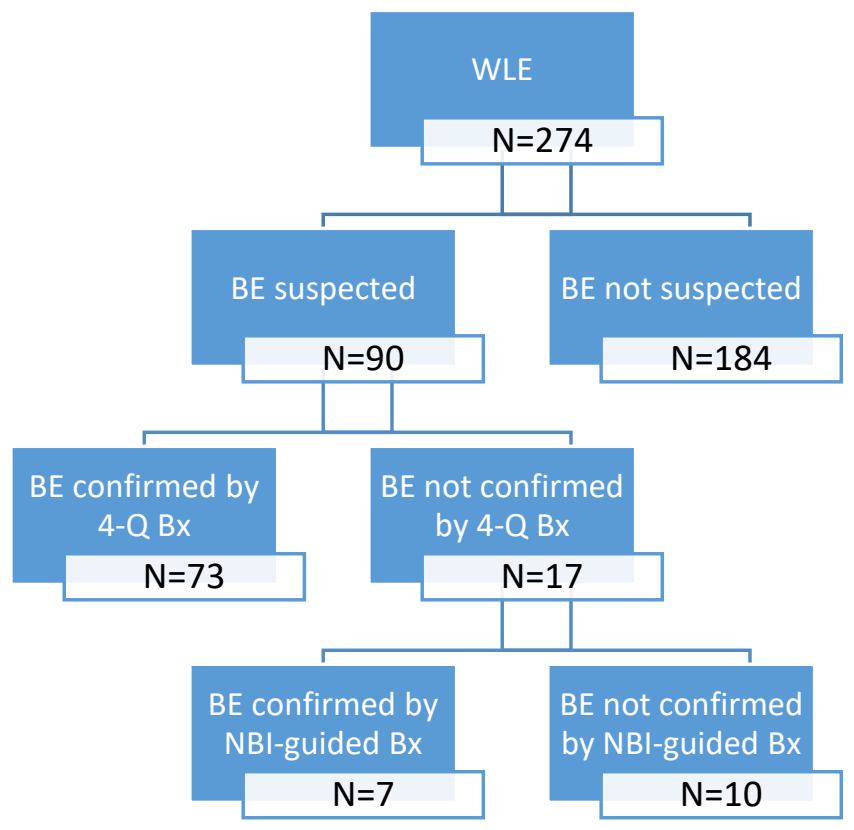

Figure (1): Flow chart of the studied cases 
Table (1) showed no statistically significant difference in the distribution of age and sex between those with and without BE. Table (2) showed no statistically significant difference in the distribution of positive Helicobacter pylori infection, BMI $\left(\mathrm{kg} / \mathrm{m}^{2}\right)$, and BMI categories between those with and without BE. Table (3) showed that performing NBI-targeted biopsy following negative result of WLE-based biopsy for cases with endoscopically suspected $\mathrm{BE}$ increases the detection of $\mathrm{BE}$ from $81.1 \%$ to 88.9\%. Although this did not achieve a statistical significance, it is of clinical concern.

Table (1): Age and sex distribution in the studied cases

\begin{tabular}{|c|c|c|c|}
\hline $\begin{array}{l}\text { Parameter } \\
\mathbf{N}\end{array}$ & $\begin{array}{c}\text { Group } 1 \text { (BE confirmed) } \\
80 \\
\end{array}$ & $\begin{array}{c}\text { Group } 2 \text { (BE not confirmed) } \\
10 \\
\end{array}$ & $P$ value \\
\hline $\begin{array}{l}\text { Age }(\text { yrs }) \\
\text { mean } \pm \text { std }\end{array}$ & $43.3 \pm 11.1$ & $30.3 \pm 10.8$ & 0.56 \\
\hline Sex & & & 0.116 \\
\hline Male & $62(77.5 \%)$ & $5(50 \%)$ & \\
\hline Female & $18(22.5 \%)$ & $5(50 \%)$ & \\
\hline
\end{tabular}

Table (2): H. pylori status and BMI in the studied cases

\begin{tabular}{llll}
\hline Parameter & Group 1 & Group 2 \\
N & 80 & 10 & P value \\
\hline Positive H. pylori & $19(23.8 \%)$ & $3(30 \%)$ & 0.72 \\
BMI (kg/m $\left.{ }^{\mathbf{2}}\right)$ & $29.2 \pm 6.8$ & $27.3 \pm 7.02$ & 0.70 \\
BMI category & & & 0.23 \\
$\quad$ Underweight & $1(1.3 \%)$ & $1(10 \%)$ & \\
Normal weight & $19(23.8 \%)$ & $1(10 \%)$ & \\
Overweight/obese & $60(75 \%)$ & $8(80 \%)$ & \\
\hline
\end{tabular}

Data expression [Test of significance]: N (\%) [Fisher's exact test] for H. pylori and BMI categories and mean \pm SD [Independent-Samples t-test] for age.

Table (3): Detection of BE by WLE-based biopsy alone (WLE) vs. WLE-based biopsy followed by NBI-targeted biopsy for cases negative by WLE-based biopsy (WLE/NBI).

\begin{tabular}{lllll}
\hline BE & WLE & WLE/NBI & $\chi^{2}$ & P value \\
\hline Positive & $73(81.1 \%)$ & $80(88.9 \%)$ & 2.135 & 0.144 \\
Negative & $17(18.9 \%)$ & $10(11.1 \%)$ & & \\
\hline
\end{tabular}

Data expression [test of significance]: N (\%) [Chi-Square test]. 


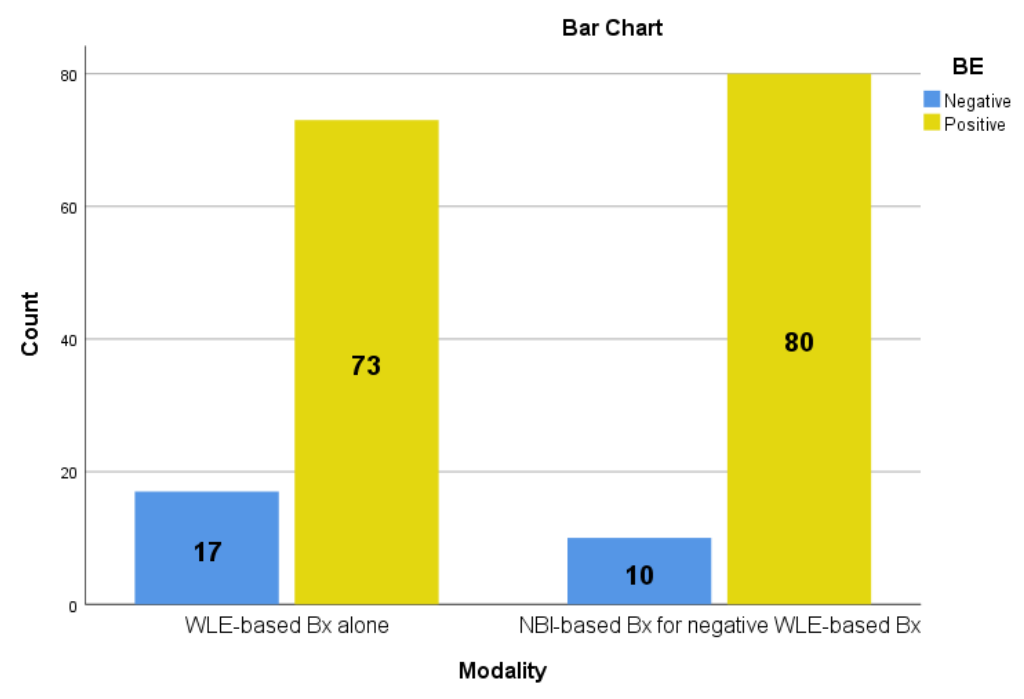

figure 2

\section{Discussion:}

The diagnosis of GERD is associated with a $10-15 \%$ risk of BE,20 the concept of metaplasia-dysplasia-carcinoma progression sequence in $\mathrm{BE}$ has led to the hypothesis that screening for BE, endoscopic surveillance to detect dysplasia, followed by endoscopic intervention, will lead to a decreased incidence of esophageal Adenocarcinoma (21) Preliminary studies suggest that NBI may represent significant improvement over standard endoscopy for detection of intestinal metaplasia within the $\mathrm{BE}$ segment and distinguish early neoplasia from nondysplastic BE (22)

This study was conducted to determine the role of NBI versus conventional white light endoscopy (WLE) in diagnosis of Barrett's esophagus in patients with chronic gastroesophageal reflux diseases.
The absolute age-specific yield of Barrett's esophagus in any particular group is poorly known in other studies, $(23,24,25,26)$. However, in our studied patients, BE were detected more with increasing age (> 30 years), this also was agreed on by other studies where Barrett's esophagus was diagnosed more commonly among older adults than younger adults,(27-30) BE occurs as a consequence of longstanding exposure of lower esophageal mucosa to acid reflux in cases with chronic GERD, which can explain development of BE in late adult and elderly, this may be an important point to define the best time of screening of patients with chronic GERD for the development of BE.

In our study, male gender was much more common than female gender in BE positive cases, this observation that male gender is an 
independent risk factor for esophagitis is

supported by other studies $(31,32,33)$, which also raise the concern of screening of $\mathrm{BE}$ more in male patients as it can be considered as a risk factor for development of BE. A recent meta-analysis study on Barrett's esophagus shows a case mix of men and women of approximately 2:1. Whether this male preponderance is the result of differences between men and women in hormonal effects on the esophagus, body fat distribution, or other as-yet unidentified factors is not clear (34).

Obesity was found to be more frequent in our studied patients with BE (75\%), this was supported by other previous studies which have suggested an association between abdominal obesity and risk of BE (35-38). For any given body mass index, subjects with higher amounts of intra-abdominal obesity, appear to have an increased risk of Barrett's esophagus.' in a recent analysis of body anthropometry in subjects with Barrett's esophagus, body mass index was no longer an independent predictor of $\mathrm{B} E$ once waistto-hip ratio was factored (39). Whether the increased risk associated with intraabdominal obesity is due to mechanical or hormonal factors or a consequence of yetundescribed factors is not known.

In our study, H. pylori test was positive in 19 of group 1 patients, and 3 of group 2 patients, while most of patients with endoscopic BE tested negative for $\mathrm{H}$ pylori (68 patients out of 90 patients) (table 2). This agreed with other studies that reported a strong inverse association between $H$. pylori and $\mathrm{BE}(0.36$; 95\% CI: 0.14-0.90), and this inverse association was explained by lower gastricacid secretion associated with $H$. pylori which may be attributed to corpus atrophy or use of antisecretory medication $(40,41)$

Of all screened patients, 90 (32.8\%) patients had endoscopic BE, 80 patients had columnar- lined intestinal metaplasia. Seventy-three patients of them was diagnosed using 4 quadrant biopsies $(81.1 \%$ of cases with endoscopic BE, and $26.6 \%$ of all screened patients), 17 patients with negative BE were re-examined and biopsied by NBI targeted biopsies, 7 patients of them proved to have BE.

$\mathrm{BE}$ prevalence in the published literature has varied based on the definition of BE used, biopsy protocol, and the study population. One study detected BE in 15\% of patients with chronic GERD (42), in another study of patients with dyspepsia, only $5 \%$ were found to have CLE, whereas CLE with intestinal metaplasia was present in $2.4 \%$.(43) Also other study evaluated patients undergoing 
screening colonoscopy for CLE with intestinal metaplasia by upper endoscopy (44).The prevalence of CLE with intestinal metaplasia in those with heartburn was about $8.3 \%$. Although these studies reported a much lower prevalence of BE, they lacked a definite biopsy protocol, besides choosing patients with different clinical diagnosis (dyspepsia in the 2nd study), and in the last study although they used a well-defined biopsy protocol, the study sample was biased toward those undergoing screening colonoscopy.

Use of NBI targeted biopsies to re-evaluate the presence of $\mathrm{BE}$ in patients with negative histopathology has increased the total number of diagnosed cases with $\mathrm{BE}$ from $81.1 \%$ to $88.9 \%$, hence we concluded that performing NBI-targeted biopsy following negative result of WLE-based biopsy for cases with endoscopically suspected $\mathrm{BE}$ increases the detection of $\mathrm{BE}$ from $81.1 \%$ to $88.9 \%$, although this did not achieve a statistical significance, it is of clinical concern (table 3, figure2). This may signify the role of NBI in accurately detecting the best site for biopsy taking to decrease sampling error and number of biopsies taken as in 4 quadrant- random biopsy technique.

In agreement with our results, another study concluded that NBI improves the visualization of important structures seen in
BE over conventional endoscopy. ${ }^{45}$ Another study compared the use of high-resolution magnified NBI with conventional WLE with magnification in patients with BE, they found that the prediction of histology in NBI group was significantly higher than conventional WLE group (46)

For evaluation of number of biopsies taken, a study found higher rate for detecting dysplasia with NBI- targeted biopsy compared with conventional endoscopy with four-quadrant biopsy technique (47). However, in another study comparing highresolution WLE with NBI in detecting early neoplasia, (48). Interestingly, the image quality was significantly better in the NBI group over the WLE group, but NBI was not found to improve the diagnostic yield of neoplasia. As they used different parameter to assess (neoplasia and not BE) this may explain the different outcome compared to our results

\section{Conclusion:}

NBI targeted biopsy could diagnose cases with BE missed by conventional endoscopy and decrease sampling error with fewer number of biopsies taken in the 4- quadrant random biopsy technique

\section{Recommendations:}

large, multicenter studies are needed for more characterization of the lesions by NBI and 
correlation with the degree of dysplasia.

\section{References:}

1. Sharma P. Clinical practice. Barrett's esophagus. N Engl J Med 2009; 361:2548-56.)

2. Jemal A, Bray F, Center MM, Ferlay J, Ward E, Forman D. Global cancer statistics. CA Cancer J Clin 2011; 61:69-90.

3. Devesa SS, Blot WJ, Fraumeni JF Jr. Changing patterns in the incidence of esophageal and gastric carcinoma in United States. Cancer 1988; 83: 2049-53.

4. Koike T, Ohara S, Shimosegawa T. Role of gastric acid secretion in the pathogenesis of Barrett's esophageal cancer in a Japanese population. Clin. J. Gastroenterol. 2009; 2: 143-8

5. Shaheen, Nicholas J MD, MPH, FACG1; Falk, Gary W MD, MS, FACG2; Iyer, Prasad G MD, MSc, FACG3; Gerson, Lauren B MD, MSc, FACG4 ACG Clinical Guideline: Diagnosis and Management of Barrett's Esophagus January 2016 - Volume 111 - Issue 1 - p 30-50 doi: 10.1038/ajg.2015.322

6. Wang KK, Sampliner RE. Updated guidelines 2008 for the diagnosis, surveillance and therapy of Barrett's esophagus. Am J Gastroenterol 2008; 103:788-97.

7. Spechler SJ, Sharma P, Souza RF, Inadomi JM, Shaheen NJ. American Gastroenterological Association technical review on the management of Barrett's esophagus. Gastroenterology 2011;140 : e18-52; quiz e13.

8. Boyer J, Laugier R, Chemali M, Arpurt JP, Boustiere C, Canard JM, et al. French Society of Digestive Endoscopy SFED guideline: monitoring of patients with Barrett's esophagus. Endoscopy 2007; 39:840-2.
9. Committee ASoP, Evans JA, Early DS, Fukami $\mathrm{N}$, Ben-Menachem T, Chandrasekhara V. et al., The role of endoscopy in Barrett's esophagus and other premalignant conditions of the esophagus. GastrointestEndosc 2012; 76:1087-94.

10. Harnish DC. Estrogen receptor ligands in the control of pathogenic inflammation. Curr Opin Investig Drugs 2006; 7:997-1001.

11. Fitzgerald RC1, di Pietro M, Ragunath K, Ang Y, Kang JY, Watson P. et al. British Society of Gastroenterology Guidelines. Diagnosis and Management of Barrett's oesophagus. Gut. 2014 Jan;63(1):7-42.

12. Sharma P, Savides TJ, Canto MI, Corley DA, Falk GW, Goldblum JR, et al. The American Society for Gastrointestinal Endoscopy PIVI (Preservation and Incorporation of Valuable Endoscopic Innovations) on imaging in Barrett's esophagus. Gastrointest ～Endosc. 2012;76:252254. [PubMed] [Google Scholar]

13. Sharma P1, Hawes RH, Bansal A, Gupta N, Curvers W, Rastogi A, et al: Standard endoscopy with random biopsies versus narrow band imaging targeted biopsies in Barrett's oesophagus: a prospective, international, randomised controlled trial. Gut 2013; 62: 15 21

14. Song LM, Adler DG, Conway JD, Diehl DL, Farraye FA, Kantsevoy SV, Kwon R, Mamula P, Rodriguez B, Shah RJ, et al. Narrow band imaging and multiband imaging. Gastrointest Endosc. 2008;67:581-589. [PubMed] [ [Google $\underline{\text { Scholar] }}$

15. Gono K, Obi T, Yamaguchi M, Ohyama N, Machida H, Sano Y, Yoshida S, Hamamoto Y, Endo T. Appearance of enhanced tissue features in narrow-band endoscopic imaging. J Biomed Opt. 2004;9:568-577. [PubMed]] 
16. Kuznetsov K, Lambert R, Rey JF. Narrow-band imaging: potential and limitations. Endoscopy. 2006;38:76-

81. [PubMed] [Google Scholar]

17. Robert M. Genta, MD,David Y. Graham, MD. Comparison of biopsy sites for the histopathologic diagnosis of Helicobacter pylori: a topographic study of $H$. pylori density and distribution Gastrointestinal Endoscopy VOLUME 40, ISSUE 3, P342-345, MAY 01, 1994

18. $\underline{\text { STUART J. PRATEEK SHARMA RHONDA }}$ F. JOHN M. NICHOLAS J. American Gastroenterological Association Technical Review on the Management of Barrett's Esophagus. Gastroenterology. 2011 Mar; 140(3): e18-e13.

18. Jung $\mathrm{KW}$, Talley NJ, Romero $\mathrm{Y}$ et al. Epidemiology and natural history of intestinal metaplasia of the gastroesophageal junction and Barrett's esophagus: a population-based study. Am J Gastroenterol 2011;106:1447-1455.

19. Nicholas J. Shaheen, Gary W. Falk, Prasad G. Iyer, and Lauren Gerson: Clinical Guideline: Diagnosis and Management of Barrett's Esophagus The American Journal of GASTROENTEROLOGY August 2015

20. Spechler SJ. Barrett esophagus and risk of esophageal cancer: a clinical review. JAMA 2013; 310: 627 - 36

21. Wani S and Sharma P: Endoscopic Surface Imaging of Barrett's Esophagus: An Optimistic View, Imaging and Advanced Technology, 2007 by the AGA Institute, .2007

22. Sharma P, McQuaid K, Dent J, Fennerty MB, Sampliner R, Spechler S, et al. A critical review of the diagnosis and management of Barrett's esophagus: the AGA Chicago Workshop.
Gastroenterology

2004;127(1):310-30.

[PubMed:15236196]

23.Wang KK and Sampliner RE. Practice Parameters Committee of the American College of G. Updated guidelines 2008 for the diagnosis, surveillance and therapy of Barrett's esophagus. American Journal of Gastroenterology 2008;103(3):788-97. [PubMed: 18341497]

24. Hirota WK1, Zuckerman MJ, Adler DG, Davila RE, Egan J, Leighton JA, et al. ASGE guideline: the role of endoscopy in the surveillance of premalignant conditions of the upper GI tract. Gastrointestinal Endoscopy 2006;63(4):570- 80.[PubMed: 16564854]

25. Watson A, Heading RC and Shepherd NA: Guidelines for the diagnosis and management of Barrett's columnar-lined oesophagus. 2005.

26. Van Soest, E.M., Dieleman, J.P., Siersema, P.D., Sturkenboom, M.C.J.M., Kuipers, E.J. Increasing incidence of Barrett's oesophagus in the general population. Gut 2005;54(8): 1062-6. [PubMed: 15857935]

27. Cameron AJ, Lomboy CT: Barrett's esophagus: age, prevalence, and extent of columnar epithelium. Gastroenterology 1992;103(4):1241-5. [PubMed: 1397881]

28. Gruppo Operat Stud Precancerosi E: Barrett's Esophagus Epidemiological and Clinical Results Of A Multicentric Survey. International Journal Of Cancer 1991;48(3):364-8.

29. Douglas A. Corley, Ai Kubo, Theodore R. Levin, Gladys Block, Laurel Habel, Wei Zhao,, et al. Race, ethnicity, sex and temporal differences in Barrett's oesophagus diagnosis: a large community-based study, 1994-2006. Gut 2009;58(2): 182-8. [PubMed: 18978173]

30. Alexander C. Ford, David Forman, P. 
Dominic Reynolds, Brian T. Cooper, and Paul Moayyedi: American Journal of Epidemiology 2005

31. El-Serag HB and Johanson JF: Risk factors for the severity of erosive esophagitis in Helicobacter pylori-negative patients with gastroesophageal reflux disease. Scand J Gastroenterol 2002; 37:899-904.

32. James R. Ramus, Christine P. J. Caygill, Neil A. Shepherd \& Anthony Watson: Relevance of the detection of intestinal metaplasia in non-dysplastic columnar-lined esophagus, 524-530, 2009 abstract, http://dx.doi.org/10.1080/003655207018798 31

33. Cook MB, Wild CP, Forman D. A systematic review and meta-analysis of the sex ratio for Barrett's esophagus, erosive reflux disease, and nonerosive reflux disease. Am J Epidemiol. 2005;162:10501061. [PubMed] [Google Scholar]

34. Corley DA, Kubo A, Levin TR, Block G, Habel L, Zhao W, et al., Abdominal obesity and body mass index as risk factors for Barrett's esophagus. Gastroenterology. 2007; 133:34-41. quiz 311. [PubMed: 17631128]

35. Edelstein ZR, Farrow DC, Bronner MP, Rosen SN, Vaughan TL. Central adiposity and risk of Barrett's esophagus. Gastroenterology. 2007; 133:403-11. [PubMed: 17681161]

36. El-Serag HB, Kvapil P, Hacken-Bitar J, Kramer JR. Abdominal obesity and the risk of Barrett's esophagus. Am J Gastroenterol. 2005; 100:2151-6. [PubMed: 16181362]

37. Edelstein ZR, Bronner MP, Rosen SN,
Vaughan TL. Risk factors for Barrett's esophagus among patients with gastroesophageal reflux disease: a community clinic- based case-control study. Am J Gastroenterol. 2009; 104:834-42. [PubMed: 19319131]

38. Kamat P, Wen S, Morris J, et al. Exploring the association between elevated body mass index and Barrett's esophagus: a systematic review and meta-analysis. Ann Thorac Surg. 2009;87:655-662. [PubMed] [Google $\underline{\text { Scholar] }}$

39. Rubenstein JH, Inadomi JM, Scheiman J, et al. Association between Helicobacter pylori and Barrett's esophagus, erosive esophagitis, and gastroesophageal reflux symptoms. Clin Gastroenterol Hepatol. 2013;3565:12317. [PMC free article] [PubMed] [Google $\underline{\text { Scholar] }}$

40. Fischbach LA, Graham DY, Kramer JR et al. Association between Helicobacter pylori and Barrett's esophagus: a case-control study. Am J Gastroenterol 2014;109:357368.

41. Johansson J, Hakansson HO, Mellblom L, Kempas A, Johansson KE, Granath F et al: Prevalence of precancerous and other metaplasia in the distal oesophagus and gastro-oesophageal junction. Scand J Gastroenterol 2005; 40: 893 - 902.

42. Veldhuyzen van Zanten SJ1, Thomson AB, Barkun AN, Armstrong D, Chiba N, White RJ, et al. The prevalence of Barrett's oesophagus in a cohort of $1040 \mathrm{C}$ anadian primary care patients with uninvestigated dyspepsia undergoing prompt endoscopy. Aliment Pharmacol Th er 2006; 23: $595-9$. 
43. Rex DK1, Cummings OW, Shaw M, Cumings MD, Wong RK, Vasudeva RS, et al. Screening for Barrett's esophagus in colonoscopy patients with and without heartburn . Gastroenterology 2003; 125: $1670-7$.

44. Yasuo Hamamoto, Takao Endo, Katsuhiko Nosho, Yoshiaki Arimura, Masaaki Sato, Kohzoh Imai. Usefulness of narrow-band imaging endoscopy for diagnosis of Barrett's esophagus. J Gastroenterol. 2004;39: 14-20. [PubMed]

45. Singh R1, Karageorgiou H, Owen V, Garsed K, Fortun PJ, Fogden E et al. Comparison of high-resolution magnification narrow-band imaging and white-light endoscopy in the prediction of histology in Barrett's esophagus. Scand J Gastroenterol. 2009;44(1):85-92 [PubMed]

46. Herbert C Wolfsen, Julia E. Crook, Murli Krishna, Sami R. Achem, Kenneth R. Devault , Ernest P. Bouras et al. Prospective, controlled tandem endoscopy study of narrow band imaging for dysplasia detection in Barrett's esophagus. Gastroenterology. 2008;135: 24-31. [PubMed]

47. W. L. Curvers, C. J. Bohmer, R. C. MallantHent, A. H. Naber, C. I. J. Ponsioen, K. Ragunath, et al. Mucosal morphology in Barrett's esophagus: Interobserver agreement and role of narrow band imaging. Endoscopy. 2008; 40:799-805. [PubMed]

To cite this article: Enaase Barakat, Maha Ragab Habeeb, Neven Farouk Abass. Role of NBI and WLE in Diagnosis of Barrett's Esophagus in Patients with Chronic Gastroesophageal Reflux Disease. BMFJ 2021;38(1):407-418. DOI: 10.21608/bmfj.2021.51085.1348 